\title{
Low-carbon scenario analysis on urban transport of one metropolitan in China in 2020
}

\author{
Xiaofei Chen ${ }^{1}$, Zijia Wang ${ }^{2}$ \\ ${ }^{1}$ Department Of Mechanical And Industrial Engineering, University Of Toronto (Canada) \\ ${ }^{2}$ School Of Civil Engineering, Beijing Jiaotong University (China) \\ xiaofei.chen@,mail.utoronto.ca,,hnғijia@gmail.com
}

Received July 2012

Accepted November 2012

\section{Abstract:}

Purpose: This paper discussed possible ways of implementing effective energy conservation and GHG emission reduction measures by providing: the forecasts of mid-to-long term citywide carbon emission rate; and the analysis of potential low-carbon transport solutions.

Design/methodology/approach: According to the characteristics of the transport system in China, based on the review and application analysis of existing transport energy and GHG emission calculation models, the comprehensive carbon emission calculation model established. Existing data were utilized with regression analysis to project the prospective traffic data in the baseline scenario at the target year of 2020 to calculate the emission amount. Four low-carbon scenarios were set in accordance with the goal of "low carbon transportation, green trip", and the effectiveness of each low-carbon scenario was evaluated by comparing them with the baseline scenario in terms of the respective GHG emission rate.

Findings: Under the current developing trend in policy environment and technical specifications, the total projected GHG $\left(\mathrm{CO}_{2}\right)$ emissions from transport sector in 2020 of the city will reach 30.085 million ton $\mathrm{CO}_{2}$; private-vehicles are the major contributor among all transport modes at 16.89 million ton $\mathrm{CO}_{2}$.

Practical implications: Limiting the growth in private-vehicle ownership, reducing the frequency of mid-to-long range travel and the average trip distance, and prompting the public 
transit oriented policies are all possible solutions to reduce carbon emission. The most effective practice involves a shift in public travel behavior.

Originality/value: This paper presents a method to forecast the mid-to-long term city-wide carbon emission rate; and provides some potential low-carbon transport solutions.

Keywords: Low carbon transport, Carbon emission, Scenario analysis, Forecasting, Energy conservation and emission reduction

\section{Introduction}

In China, the negative environmental consequences caused by GHG emission from transport sector in metropolitan regions grow rapidly along with continuous urbanization process. Against the background of high-speed economic development, the growing household consumption capability in metropolitan results in a dramatic increase of urban residential trips, which enlarges carbon emission contribution from urban passenger traffic (He \& Huo, 2005).

In fact, total GHG emission volume stays at a very high level, despite of recent achievements of traffic and purchase restrictions upon household automobile and actions that encourages the utilization of rail transportation.

We set up baseline and relevant low-carbon scenarios to forecast total GHG emission from transport industry in one metropolitan in China, and evaluate the implemented energy conservation and emission reduction policies, such as "public transit priority". These are of great significance to this metropolitan and even to the whole country for coming up with effective strategies to control the GHG emission and assume its commitment to emission reduction.

\section{GHG emissions calculation model of transport section}

In reference to field study, literature review, and collectable data, the research scope of this paper is as following: firstly, only $\mathrm{CO}_{2}$ is taken into account in terms of types of $\mathrm{GHG}_{1}$; for vehicle genre, only local registered vehicles are covered; and for transport modes, this research mainly involves road transport (including urban road, express highway and highway) and rail transit in This metropolitan.

Our research starts with setting up calculation models for each type of fuel on roads to examine the overall energy consumption. In accordance with terminal consumption of each energy resource, the formulas are as follows. 
For diesel fuel:

$$
E_{\text {diesel }}=Q_{f} e_{f}+N_{d-\text { bus }} S_{d-\text { bus }} e_{d-\text { bus }}
$$

Where $E_{\text {diesel }}$ is the consumption of diesel fuel, $Q_{f}$ for the ton kilometer traveled per year (ton·km) (Beijing Municipal Bureau of Statistics, 2010), $e_{f}$ for the fuel economy (L/(ton·km))(Jia, Peng \& Liu, 2009), $N_{d-b u s}, S_{d-b u s}, e_{d-b u s}$ for the vehicle population, kilometers traveled per year $(\mathrm{km})$, and fuel economy $(\mathrm{L} / \mathrm{km})$ of diesel buses, respectively.

For gasoline:

$$
E_{\text {gasoline }}=\sum_{i=1}^{3} N_{i} S_{i} e_{i}
$$

Where $E_{\text {gasoline }}$ refers to gasoline consumption, $i$ for relevant vehicle category, including taxis, private cars and cars owned by enterprises and public institutions, $N_{i}$ for vehicle population of vehicle category $i, S_{i}$ for kilometer traveled per year of vehicle category $i, e_{i}$ for fuel economy of vehicle category $i(\mathrm{~L} / \mathrm{km})$.

For compressed natural gas:

$$
E_{g a s}=N_{g-b u s} S_{g-b u s} e_{g-b u s}
$$

Where $N_{g-b u s}, S_{g-b u s}, e_{g-b u s}$ refers to vehicle the population, kilometer traveled per year (km), and fuel economy $(\mathrm{kg} / \mathrm{km})$ of compressed natural gas driven buses, respectively.

And for electricity consumption:

$$
E_{e}=N_{e-b u s} S_{e-b u s} e_{e-b u s}+E_{i l l u}+\sum_{j=1}^{n} E_{j-\text { vehicle }}+\sum_{j=1}^{n} \sum_{k=1}^{n} E_{j k-\text { station }}
$$

Where $N_{e-b u s}, S_{e-b u s}, e_{e-b u s}$ denotes the vehicle population, kilometer traveled per year $(\mathrm{km})$, and fuel economy $(\mathrm{kg} / \mathrm{km})$ of electricity-based buses, respectively; $E_{\text {illu }}$ for electricity consumed by a road illumination system, which is recorded by power department, and $E_{j \text {-vehicle }}$ , $E_{j k-s t a t i o n}$ refer to the vehicle energy consumption of rail line $j$ and the station energy consumption of station $k$ in rail line $j$, respectively. 
Using the energy consumption obtained through the above models and the $\mathrm{CO}_{2}$ emission factor of each fuel category from ICPP (Intergovernmental Panel on Climate Change), in combination with the proportion of coal electricity out of overall electricity supply and $\mathrm{CO}_{2}$ emission factor for electricity generation in the grid, the overall GHG emission of this metropolitan's urban transport can be calculated with the following formula:

$$
C=\sum_{i=1}^{3} E_{i} \times E F_{i}+E_{e} \times \zeta \times \psi
$$

Where $C$ denotes the overall GHG emission of urban transport per year; $E_{i}$ stands for consumption of fuel category $i$, including diesel fuel, gasoline, compressed natural gas ( $L$ or $\mathrm{kg}) ; E F_{i}$ is the emission factor for fuel category $i\left(\mathrm{~kg} \mathrm{CO}_{2} / \mathrm{L}\right.$ or $\left.\mathrm{kg} \mathrm{CO} / \mathrm{kg}\right) ; E_{e}$ refers to electricity consumption of transport, including consumption of electricity-based buses, road illumination system and urban rail transit system $(\mathrm{k} \cdot \mathrm{Wh}) ; \boldsymbol{\varsigma}$ denotes the sharing of coal electricity out of overall electricity generated in the grid, which is $81.81 \%$ (China Electricity Council, 2011); $\psi$ is $\mathrm{CO}_{2}$ emission factor for coal electricity during generation stage in the grid $(\mathrm{Ma}, 2002)\left(\mathrm{CO}_{2} \mathrm{~kg} / \mathrm{k} \cdot \mathrm{Wh}\right)$.

\section{Scenario analysis on GHG emissions of Urban Transport in 2020}

This paper examines two major categories of scenarios assumed in the long-term urban planning of this metropolitan, including baseline scenario and low-carbon scenarios. The plan sets 2020 as its target year. As to baseline scenarios, they are introduced in consideration the trend of the transport infrastructure, socio-economic features, existing vehicle techniques and transport policies. The GHG emission is projected. When it comes to low-carbon scenarios, they are assumed according to the concept of "low carbon transportation, green trip", which applauses for vehicle purchase control, traffic sharing, and short-distance trips. We calculate GHG emission of each and make comparison between them.

\subsection{Baseline Scenario}

As for road transport, the calculation parameters including tonnes-kilometres travelled of freight per year and the vehicle population of buses is projected through the regressive relationship with respect to GDP.

In consideration of vehicle population control policy of this metropolitan, the projected population of taxis and non-operating cars still need to be adjusted and controlled. With the projected parameters, the GHG emission can be calculated through the model established above. 
As for rail transit, due to the difference between the calculation methods in the present and the future, the vehicle energy consumption per ton per kilometer and the average energy consumption per station of different conditioning type are excepted and used as basic parameter for future energy consumption of urban rail transit network.

\section{1) Projection of Per capita GDP}

According to the Statistical Yearbook (1999-2011), in combination with the population supporting capacity of this metropolitan (Ma \& Hou, 2004), the population of this urban registered residents in 2020 can be drawn based on model in formula 6. According to the long term economic development planning in this metropolitan, annual growth rate of GDP is assumed to be $8 \%$. And the GDP of research target in 2020 is able to be predicted. Then the GDP per capita in 2020 will be got.

$$
R=9.66 \times 10^{8} \ln (t)-7.333 \times 10^{9}
$$

In the formula, $R$ denotes the residential population in year $t$.

\section{2) Urban Road Transport Energy Consumption Projection}

As shown in formula 7 and 8 , freight volume and bus population are in a regressive relationship with GDP per capita. It freight volume $Q_{f}$ of this urban in 2020 can be estimated, so does the bus population $N_{\text {bus, }}$ of which the proportion of vehicle driven by diesel fuel, by electricity and by CNG is $9.266: 1: 2.235$. In baseline scenario, each bus runs the same mileage as that in 2011.

$$
Q_{f}=3.51 \times 10^{9} \exp \left(9.86 \times 10^{-6} G\right)
$$

In the formula, $Q_{f}$ denotes the freight volume in ton· $\mathrm{km}$, and $G$ is GDP per capita.

$$
N_{\text {bus }}=0.1367 G+11623
$$

Of which $N_{\text {bus }}$ denotes the bus population, and $G$ is GDP per capita.

As for taxis, according to "Notice on Adjustment of Small Passenger Car Registration" (Beijing Transport Management Bureau, 2009) issued by Traffic Management Bureau of this urban, the taxis number will be strictly controlled to be the present level, and the mileage per vehicle per year remains the present value. 
Meanwhile, the increase of non-operating cars should not exceed 240,000 each year. In consequence, population of non-operating car in 2020 will be easily drawn, and the mileage per car per year in target year is taken as the present value.

As for road illumination system, assuming the energy consumption increases by evenly each year, the total consumption is predicted in 2020 .

3) Projection Model of the Energy Consumption of Urban Rail Transit

With regard to vehicle energy consumption, it is can be calculated with the basic index $\eta$ through index method, which signifies energy consumption of rail transit in unit ton kilometre. It is calculated by formula 9 with present energy consumption and line feature data.

$$
\eta=E /(2 W \times N \times L+P \times D \times 60 / 1000)
$$

In the formula, $\eta$ denotes energy consumption per TKT $(\mathrm{k} \cdot \mathrm{Wh} /$ ton $\cdot \mathrm{km}) ; E$ is energy consumption per year $(\mathrm{kwh}) ; W$ is train weight $(\mathrm{t}) ; N$, annual number of train departures; $L$, operating mileage $(\mathrm{km}) ; P$, passenger volume, assumed to have an average weight of $60 \mathrm{~kg} ; D$, average trip distance $(\mathrm{km})$.

With the help of formula 10, we can come up with total vehicle energy consumption by including future rail network planning data into consideration.

$$
E_{v i}=(2 W \times N \times L+P \times D \times 60 / 1000) \times\left(\eta_{1} \times l_{1} / L+\eta_{2} \times l_{2} / L\right)
$$

$E_{v i}$ suggests vehicle energy consumption of line $i$ per year; $\eta_{1}$ and $\eta_{2}$ denote energy consumption per TKT underground and surface lines, respectively; $l_{1}$ and $l_{2}$, mileage of underground and surface lines, respectively.

For station energy consumption, rail stations are classified into 3 types according to laying approach and environment control systems. Energy consumption per station per month of each type is recorded, and this provides the research with data base. With the help of all these, future station energy consumption can be forecasted through formula 11:

$$
E_{s i}=\sum\left(n_{1} \times E_{i 1}+n_{2} \times E_{i 2}+n_{3} \times E_{i 3}\right)
$$

$E_{s i}$ denotes station energy consumption of line $i ; n_{1}, n_{2}, n_{3}$ are the number of stations using ground open system, underground open system and platform door system as environment control system, respectively; and $E_{1}, E_{2}, E_{3}$ are for energy consumption of each type of station as mentioned above, respectively. 
Furthermore, the long-term rail transit network planning of this metropolitan declares that the mileage of rail transit will reach to 1,050 kilometers in 2020 with 450 stations. Taking advantage of this information and the projection models, total network energy consumption and the corresponding GHG emission can be forecasted with formula 5.

3) GHG emission for baseline scenario

To support the forecasts of GHG emission, not only does the research make use of the models established above, but also takes into account the 2011 data (table 1) (Hao,Wang \& Li, 2009; Ministry of Industry and the Ministry of Information, 2011; Transportation Research Center, 2011), concerning energy consumption and emission.

\begin{tabular}{|c|c|r|r|}
\hline Vehicle types & Fuel type & Energy economy & Emission factor \\
\hline Freight & diesel & $0.1079 \mathrm{~L} / \mathrm{tkm}$ & $2.73 \mathrm{~kg} / \mathrm{L}$ \\
\hline \multirow{3}{*}{ Buses } & diesel & $40.12 \mathrm{~L} / 100 \mathrm{~km}$ & $2.73 \mathrm{~kg} / \mathrm{L}$ \\
\cline { 2 - 4 } & electricity & $0.9646 \mathrm{k} \cdot \mathrm{Wh} / \mathrm{km}$ & $1.019 \mathrm{~kg} / \mathrm{k} \cdot \mathrm{Wh}$ \\
\cline { 2 - 4 } & CNG & $35 \mathrm{~kg} / 100 \mathrm{~km}$ & $2.26 \mathrm{~kg} / \mathrm{L}$ \\
\hline Taxis & gasoline & $7.58 \mathrm{~L} / 100 \mathrm{~km}$ & $2.26 \mathrm{~kg} / \mathrm{L}$ \\
\hline Social cars & gasoline & $7.76 \mathrm{~L} / 101 \mathrm{~km}$ & $2.26 \mathrm{~kg} / \mathrm{L}$ \\
\hline
\end{tabular}

Table 1. Energy economy and emission factor for various vehicle and fuel types

The results project the GHG emission of baseline scenario for this metropolitan's urban transport in the target year 2020, which is 30.085 million ton CO2. The GHG emission sharing of freight transport, buses, taxis, non-operating cars, road illuminating system and rail transit are $2.580 \times 10^{6}, 1.986 \times 10^{6}, 2.112 \times 10^{6}, 2.061 \times 10^{7}, 4.19 \times 10^{5}, 2.378 \times 10^{6}$ ton $\mathrm{CO}_{2}$, respectively.

\subsection{Low carbon scenarios}

Scenario 1: Take more strict control on vehicle population growth

The population of non-operating cars will reach 5.96 million in 2020 according to baseline scenario. It is necessary to hold more strict control on the growth of vehicle quantity to ensure the number of private cars and buses not to exceed 5 million in 2020. In that case, the GHG emission of this metropolitan's transport will be 28.203 million ton $\mathrm{CO}_{2}$, with a reduction of 1.882 million ton $\mathrm{CO}_{2}$, equal to a minus $6.26 \%$ compared with the baseline scenario.

Scenario 2: Decrease average trip distance

Optimization of urban layout will result in gradual decrease in average residential trip distance. In the baseline scenario, the average trip distance of non-operating cars is $10.78 \mathrm{~km}$; and that of rail transit is $16.35 \mathrm{~km}$ (Traffic Development Annual Report, 2011). However, in a lowcarbon scenario, average trip distance of private car is $8 \mathrm{~km}$, and that of rail transit is $12 \mathrm{~km}$. 
Under the latter situation, the GHG emission of transport will be 25.648 million ton $\mathrm{CO}_{2}$, with an emission reduction of 4.437 million ton $\mathrm{CO}_{2}$ or of $14.75 \%$ compared with the baseline scenario.

Scenario 3: Increase the ridership of public transport

In the baseline scenario, the structure of ridership in this metropolitan is: $28.9 \%$ by bus, $10.0 \%$ by urban rail transit, $7.1 \%$ by taxi, and $34.0 \%$ by non-operating cars.

With the introduction of the "public transit priority" policy, significant changes are taking place in the development of public transportation in this metropolitan. Particularly, rail transit network is booming and its ridership increases remarkably. Consequently, the municipal government sets the low-carbon scenario as follows: In 2020, the ridership of public transportation will account for $50 \%$. To be more specific, the ridership of buses will be $20 \%$; urban rail transit, 30\%; taxi, 5\%; and bicycles, $25 \%$. In contrast, the use of private cars will decrease to $15 \%$, and the rest share of trip is assumed by walking. In terms of the scenario setting, GHG emission in 2020 will be 23.426 million ton $\mathrm{CO}_{2}$, achieving a decrease of 6.659 million ton $\mathrm{CO}_{2}$, or $24.13 \%$ compared with the baseline scenario.

\begin{tabular}{|c|r|r|r|r|}
\hline Scenarios & $\begin{array}{c}\text { Baseline } \\
\text { scenario }\end{array}$ & $\begin{array}{c}\text { Low-carbon } \\
\text { scenario 1 }\end{array}$ & $\begin{array}{c}\text { Low-carbon } \\
\text { scenario 2 }\end{array}$ & $\begin{array}{c}\text { Low-carbon } \\
\text { scenario 3 }\end{array}$ \\
\hline GHG emissions (million tCO2) & 30.085 & 28.203 & 25.648 & 23.426 \\
\hline Emission reduction (million tCO2) & $/$ & 1.882 & 4.437 & 6.659 \\
\hline Proportion (\%) & $/$ & 6.26 & 14.75 & 22.13 \\
\hline
\end{tabular}

Table 2. Comparison of Scenarios 1, 2 and 3

\section{Conclusion and Suggestions}

Based on the researches completed, the article has reached the following conclusions:

- In the current developing trend in policy environment and technical specifications, total GHG $\left(\mathrm{CO}_{2}\right)$ emission from transport sector in 2020 of the city will reach to 30.085 million ton $\mathrm{CO}_{2}$. Private vehicles are the major contributor among all transport modes, emitting 16.89 million ton $\mathrm{CO}_{2}$.

- As indicated by the analysis of low carbon scenarios, restricting the growth of privatevehicle ownership, shortening trip distance in average, and promoting "public transit priority" policies are all solutions to reduce $\mathrm{CO}_{2}$ emission. The most effective way is to prompt a shift in public travel behaviour.

Meanwhile, the article also likes to provide a number of suggestions with regard to reducing transport GHG emission: 
- It is believed that it is necessary to speed up the constructions of urban rail transit, improve service quality of public transport, to optimize " $P+R$ " facilities and public bicycle rental system, to advocate trip by bicycle and walking, to promote the change in transportation mode, and to increase the ridership of public transit.

- The success of emission controlling can't be reached without contribution of individuals. We advocate integrated community development because it can address part of the travel demands within the community, and further reduce the need for mid and long distance travels. Meanwhile, we should avoid functional agglomeration redundancy in urban planning and land use.

- Except some traditional policies, e.g. vehicle purchase restrictions, we should take further measures to induce more economical use of private cars through differentiated charges on parking in certain regions.

\section{References}

Beijing Municipal Bureau of Statistics. (2010). 2010 Beijing Statistical Yearbook.

Beijing Transport Management Bureau. (2009). Notice on adjustment of small passenger car registration in Beijing. http://www.bjjtgl.gov.cn/publish/portal1/ tab167/info21977.htm.

China Electricity Council. (2011). The percentage of Thermal power of Total Generating Capacity. http://tj.cec.org.cn/.

Hao, H., Wang, H.W., \& Li, X.H. (2009). Energy conservation and emission reduction of natural gas based alternative vehicle fuels. Natural Gas Industry, 29(4), 96-98.

$\mathrm{He}$, K.B, \& Huo, H. (2005). Oil consumption and $\mathrm{CO}_{2}$ emissions in China's road transport:current status, future trends, and policy implications. Energy Policy, 33, 1499-1507. http://dx.doi.org/10.1016/j.enpol.2004.01.007

Intergovernmetal Panel on Climate Change. (2006). Intergovernmental Panel on Climate Change Report.

Jia, S.P., Peng, H.Q., \& Liu, S. (2009). Review of Transportation and Energy Consumption Related Research. Journal of Transportation Systems Engineering and Information Technology, 9 (3), 6-16. http://dx.doi.org/10.1016/S1570-6672(08)60061-6

Ma, Z.H. (2002). Evaluation studies of several major energy greenhouse gas emission factors. China Institute of Atomic Energy, thesis.

Ma, X.H., \& Hou, Y.F. (2004). A Study on Beijing's Population Variation Trend in the Future 50 Years. Market and Demographic Analysis, 10(2), 46-50. 
Ministry of Industry and the Ministry of Information. (2011). Light vehicle fuel consumption notice. http://gzly.miit.gov.cn:8090/datainfo/miit/babs2.jsp.

Transportation Research Center. (2011). 2011 traffic development annual report.

Journal of Industrial Engineering and Management, 2012 (www.jiem.org)

El artículo está con Reconocimiento-NoComercial 3.0 de Creative Commons. Puede copiarlo, distribuirlo y comunicarlo públicamente siempre que cite a su autor y a Intangible Capital. No lo utilice para fines comerciales. La licencia completa se puede consultar en http://creativecommons.org/licenses/by-nc/3.0/es/ 